\title{
Chronic melanocortin 4 receptor blockage causes obesity without influencing sexual behavior in male rats
}

\author{
A V Vergoni, A Bertolini, G Guidetti, V Karefilakis, M Filaferro, \\ J E S Wikberg ${ }^{1,2}$ and $H$ B Schiöth ${ }^{2,3}$
} Department of Biomedical Sciences, Section of Pharmacology, University of Modena and Reggio Emilia, Modena, Italy
${ }^{1}$ Department of Pharmaceutical Pharmacology, Uppsala University, Uppsala, Sweden
${ }^{2}$ Melacure Therapeutics AB, Uppsala, Sweden
${ }^{3}$ Department of Neuroscience, Uppsala University, Uppsala, Sweden
(Requests for offprints should be addressed to H B Schiöth, Department of Neuroscience, Biomedical Center, Box 593, 75124 Uppsala, Sweden; Email:
helgis@bmc.uu.se or A V Vergoni, Department of Biomedical Sciences, Section of Pharmacology, University of Modena and Reggio Emilia, Via G. Campi
287, 41100 Modena, Italy; E-mail: vergoni@unimo.it)

\begin{abstract}
We investigated the effects of continuous intracerebroventricular infusion of a melanocortin 4 receptor antagonist HS014 (cyclic $\left[\mathrm{AcCys}^{11}, \mathrm{D}-\mathrm{Nal}{ }^{14}, \mathrm{Cys}^{18}, \mathrm{Asp}^{10} \mathrm{NH}_{2}{ }^{22}\right] \beta$ MSH-(11-22)) over 12 days and a subsequent 12-day recovery period on food intake, body weight and copulatory behavior in male rats. The results show that the food intake increased immediately after the start of the infusion of HS014 $(0 \cdot 16 \mathrm{nmol} / \mathrm{h})$ and progressively increased thereafter. No tachyphylaxis was observed. When the infusion of HS014 was terminated, the foodintake levels dropped. The body weights of the rats had increased by $17 \%$ by the end of the study, compared with controls. During the recovery period, the body weight decreased towards the levels of the control rats. These results indicate that overeating and the subsequent
\end{abstract}

increases in body weight caused by blockage of the melanocortin 4 (MC4) receptor are reversible when the blockage is ended. We also tested the copulatory behavior of vigorous male rats in the presence of female rats in estrous. We registered mount latency, the number of mounts, the intromission latency, the number of intromissions, the ejaculation latency and the post-ejaculatory interval three times during the study and also after acute administration of HSO14 and $\alpha-\mathrm{MSH}$. The sexual behavior of the male rats was not affected. These results indicate that the MC receptors, in particular the MC4 receptor, may not be a major mediator of effects on copulatory behavior in male rats.

Journal of Endocrinology (2000) 166, 419-426

\section{Introduction}

The melanocortic peptides (melanocyte-stimulating hormone $(\mathrm{MSH})$ and adrenocorticotropin $(\mathrm{ACTH})$ ) have a broad array of physiological effects. The effects of the melanocortins on peripheral functions, such as steroidoneogenesis in the adrenal gland and skin or hair pigmentation, are probably those which are most thoroughly characterized. Other peripheral effects of melanocortins, such as those on inflammation (Lipton \& Catania 1997) and the cardiovascular system (Guarini et al. 1999), are receiving increased attention. The central effects of the melanocortins are, however, much more diverse and complex. One of the reported effects of melanocortins is that on sexual behavior. The first reports are from the mid-1960s: ACTH was reported to cause sexual excitement in male rabbits (Bertolini et al. 1968, 1969). The sexual response consisted of penile erection followed by copulatory movements and ejaculations in the absence of females. $\alpha-\mathrm{MSH}$ induced similar responses in rats (Bertolini et al. 1975). ACTH can be processed into ACTH(1-13), which has the same amino acid sequence as $\alpha-\mathrm{MSH}$, and it is conceivably the MSH pharmacophore which is responsible for the actions for ACTH in this respect (Schiöth et al. 1997).

The melanocortins are also important in the hypothalamic regulation of food intake. It was already discovered in the 1980s (Poggioli et al. 1986, Vergoni et al. 1986) that melanocortins influence food intake, but it was only recently shown (by knock-out studies in mice) that these effects are mediated through the melanocortin 4 (MC4) receptor (Huzsar et al. 1997). The MC4 receptor is one of five subtypes in the family of melanocortin receptors which bind, and are activated by, the melanocortic peptides. The MC4 receptor knock-outs showed characteristics similar to those of mice overexpressing the agouti peptide, which is an antagonist for this receptor (Lu et al. 1994). Administration of a MC4 receptor agonist leads to 
acute reduction in food intake and body weight, while the reverse effects are observed after administration of a MC4 receptor antagonist (Fan et al. 1997, Grill et al. 1998, Kask et al. 1998, Vergoni et al. 1998). The potential use of MC4 receptor agonists against obesity has attracted a great deal of interest. Moreover, as MC4 receptor blockage reduces stress-induced anorexia (Vergoni et al. 1999), it has been speculated that MC4 receptor antagonists may become useful in the treatment of different anorectic conditions.

It is still not known which of the MC receptors mediates the effects of melanocortins on sexual behavior. Moreover, it is not known if there are any links between the effects of the melanocortins on food intake and sexual behavior. In this study, we treated male rats with continuous i.c.v. infusion of a selective MC4 receptor antagonist for 2 weeks and monitored the food intake and body weight during this period and additionally for a further 2 weeks after the infusion had been terminated. We also investigated the effects of this treatment, which caused obesity, on sexual behavior. Moreover, in another setting we tested the effect of acute administration of a MC4 receptor antagonist and $\alpha-\mathrm{MSH}$ on sexual behavior in male rats.

\section{Materials and Methods}

\section{Animals and surgery}

Adult Sprague-Dawley male rats (Harlan Nossan, Correzzana, Italy), weighing 175-200 g at the beginning of the experiments, were housed in climatically controlled colony rooms $\left(21 \pm 1{ }^{\circ} \mathrm{C} ; 60 \%\right.$ humidity) with a reversed light/darkness cycle $(12 \mathrm{~h} / 12 \mathrm{~h}$; lights on from 2000 $0800 \mathrm{~h}$ ) and had free access to food and water. After a 3 -week period of stabilization to the new light/darkness cycle, the rats were subjected to five preliminary copulatory tests (see below for details) and then either implanted with a stainless steel guide cannula (for acute i.c.v. treatments) or with a cannula connected to a microosmotic pump (for chronic administration of a drug). Age-paired females of the same strain served as sexual partners and were housed in the same conditions and subjected to ovariectomy 3 weeks before the start of the sexual activity tests; they were then brought into estrous by sequential treatment with estradiol monobenzoate (s.c., $15 \mu \mathrm{g} 48 \mathrm{~h}$ before testing) and progesterone (s.c., $1000 \mu \mathrm{g}$ $4 \mathrm{~h}$ before testing). All surgical procedures were done under anesthesia using ketamine plus xylazine (i.p., $115+2 \mathrm{mg} / \mathrm{kg}$; Farmaceutici Gellini (Aprilia, Italy) and Bayer (Milano, Italy) respectively). All experiments were performed in accordance with local (D.L.vo 116/92) and international guidelines for animal experiments (European Communities Council Directive 86/609/EEC). For the acute administrations, a stainless steel guide cannula (22gauge) (Plastic Products Co., Roanoke, VA, USA) was stereotaxically implanted to a depth of $0.5 \mathrm{~mm}$ above a lateral brain ventricle (measured in $\mathrm{mm}$ from the bregma: anterior posterior $=-0 \cdot 8$; lateral $=1 \cdot 4$; ventricular $=3 \cdot 25$ ) (Paxinos \& Watson 1982) and fixed to the skull with screws and dental acrylic. A removable plug was kept in place except during the drug injections. Correct placement was verified at the end of the experiment by the injection of $2 \mu$ loluidine blue dye through an internal cannula (28-gauge) used for drug (or saline) injection (which extended $0.5 \mathrm{~mm}$ below the tip of the implanted guide cannula), followed by decapitation, under ethyl ether anesthesia, and dissection of the brain. Data obtained from improperly implanted animals were discarded. For the chronic treatments, a brain infusion cannula (Alzet Brain Infusion Kit, Alza Co., Palo Alto, CA, USA) was stereotaxically implanted intracerebrovascularly at the same co-ordinates as above. The cannula was connected by tubing to the flow moderator of an Alzet microosmotic pump (Model 1002). All components were previously filled with saline $(\mathrm{NaCl} 0.9 \%)$ or with drug solution and left in saline at $37^{\circ} \mathrm{C}$ for $48 \mathrm{~h}$ prior to the implantation. The pump and the tubing extended subcutaneously along the back between the scapulae, so that when the wound was closed all the components were located beneath the skin. The i.c.v. infusion lasted for 12 days and the rats received the solution at a constant rate $(0 \cdot 25 \mu \mathrm{l} / \mathrm{h})$. At the end of the infusion period, animals were anesthetized and the pumps were disconnected from the i.c.v. cannulae and then removed. Animals were weighed every day, as was the amount of food eaten during the whole infusion period and for 11 days after the cessation of infusion.

\section{Drugs and treatments}

HS014 (Schiöth et al. 1998) (cyclic $\left[\mathrm{AcCys}^{11}\right.$, D-Nal ${ }^{14}$, $\left.\mathrm{Cys}^{18}, \mathrm{Asp}-\mathrm{NH}_{2}{ }^{22}\right] \quad \beta-\mathrm{MSH}-(11-22)$ ) was provided by Melacure Therapeutics AB (Uppsala, Sweden) and $\alpha-\mathrm{MSH}$ was purchased from Neosystem (Strasbourg, France).

For the chronic treatments, HS014 was dissolved in saline to ensure release at $0.16 \mathrm{nmol} / \mathrm{h}(0 \cdot 27 \mu \mathrm{g} / \mathrm{h})$. For the acute treatments, the peptides were freshly dissolved in saline and injected intracerebrovascularly, at doses of 5, 7.5 or $10 \mu \mathrm{g}$ HSO14 per rat and 5 or $10 \mu \mathrm{g} \alpha-\mathrm{MSH}$ per rat, of in a volume of $5 \mu \mathrm{l}$ and at a rate of $1 \mu \mathrm{l}$ per $20 \mathrm{~s}$ via an i.c.v. internal cannula that protruded $0.5 \mathrm{~mm}$ beyond the guide cannula tip, connected by polyethylene tubing to a $50 \mu \mathrm{l}$ syringe (Hamilton, Bonadure, Switzerland) driven by a micrometric screw.

\section{Sexual behavior study}

All of the copulatory tests (before, during or after the treatment, as indicated in the results section) were performed starting $3 \mathrm{~h}$ after lights off under a red light, according to the standard procedure (Dewsbury 1972, Sachs \& Barfield 1976). The rats were put in a mating 
arena in the presence of a receptive female and the following parameters were recorded: mount-mount with pelvic thrusting; intromission-mount with vaginal penetration; ejaculation-mount with intromission and a final prolonged thrust, slow dismounting, and genital grooming; mount latency and intromission latency time to first mount and intromission, respectively; ejaculation latency time from first intromission to ejaculation; and post-ejaculation interval time from ejaculation to first intromission of a new series. The test was ended after the first post-ejaculatory intromission or when the mount or intromission latency was $>15$ min, when the ejaculation latency was $>30$ min or when the post-ejaculation interval was $>15$ min. Rats were included in the study irrespective of sexual performance; however, all of them satisfied the criteria for sexual vigor (defined as the ability to achieve ejaculation within the cut-off time-limit in at least two out of five preliminary tests).

\section{Statistics}

Data concerning sexual performance were expressed as medians \pm interquartile ranges and were analyzed in the acute experiments using an overall Kruskal-Wallis analysis of variance (ANOVA) for non-parametric data, followed by the Mann-Whitney $U$ test when ANOVA revealed differences among groups; the Mann-Whitney $U$ test was used alone in the chronic experiments since only two groups were tested. Data concerning body weight and food intake in the chronic experiments were expressed as means \pm S.E.M.values and were analyzed with the Student's t-test. A $P$ value $<0 \cdot 05$ was considered as statistically significant.

\section{Results}

We investigated the effects of chronic 12-day administration of HS014 on food intake, body weight and copulatory behavior in male rats. Moreover, we tested the effects of an acute single-dose administration of HS014 on copulatory behavior in male rats. The results on food intake are shown in Fig. $1 a$ and those on body weight in Fig. 1b. The results show that there was already a significant increase in food intake by the second day of the infusion of HS014, compared with the controls. The difference between the groups increased until the 7th day of the infusion and then the food-intake levels were maintained throughout the infusion period. On the 12th day of the infusion, the HS014-treated rats ate $92 \%$ more than the control group. The pumps were disconnected on Day 12 and we carefully monitored the food intake during the additional 12 days. When the infusion was terminated, the food intake gradually decreased in the group that had been treated with HS014. At Day 16, 4 days after the end of the infusion, the food intake was not significantly different between the groups. The HS014-treated rats (a)

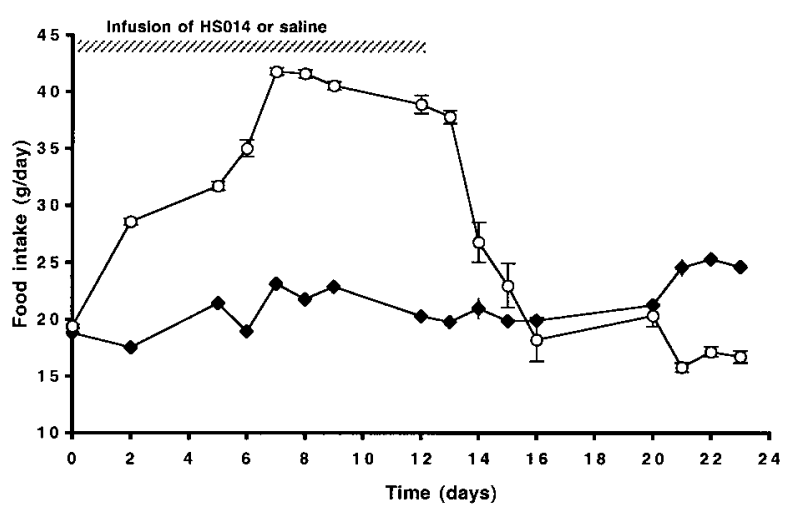

(b)

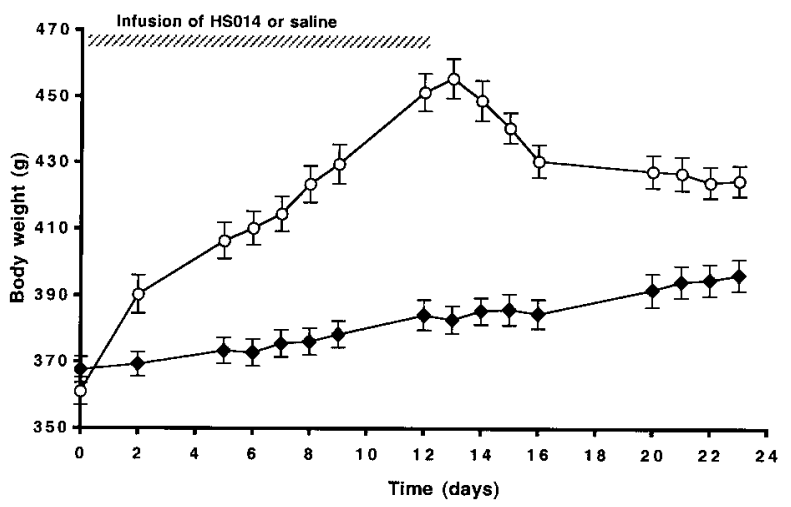

Figure 1 Influence of chronic infusion of $(\bigcirc) \mathrm{HS} 014$

$(0 \cdot 16 \mathrm{nmol} / \mathrm{h})$ or $(\bullet)$ saline on (a) food intake or $(b)$ body weight in Sprague-Dawley male rats. All values represent mean \pm S.E.M. values; $n=14-16$ per group.

continued to lower their food intake and at Day 21 the HS014 group had a significantly lower food intake than the control group. This difference was still observed when the study was terminated at Day 24, 12 days post-infusion.

The results on body weight (Fig. 1b) reflect the results on food intake. By the second day of infusion the HS014 treated rats were already significantly heavier than the controls. The difference between the two groups continued to increase during the whole period. The HS014 rats weighed $17 \cdot 5 \%$ more than their controls at day 12 of the infusion. The HS014 rats lost weight after termination of the infusion but they were still $7 \cdot 2 \%$ heavier than the controls when the study was terminated.

We tested the sexual behavior of the rats three times during the investigation period. The data are shown in Table 1. None of the parameters tested (mount latency, number of mounts, intromission latency, number of intromissions, ejaculation latency, post-ejaculatory interval) differed in the HS014 group compared with the controls at the 5 th or 12 th days of the infusion or at the 2 nd day after 


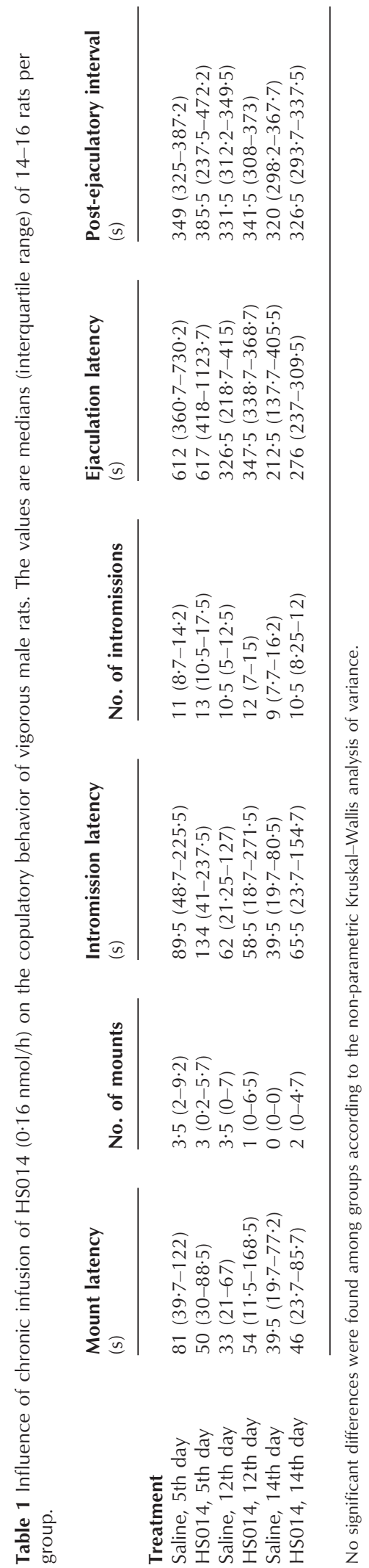


the infusion had been stopped. Moreover, separate tests were conducted to determine if i.c.v. administration of three different single doses of HS014 affected sexual behavior in male rats. The results, which are shown in Table 2, do not show differences between the controls and the treated rats. The mount latency is a little prolonged at the highest dose of HSO14 but, as this is not reflected in any other parts of the data, we are not willing to draw any major conclusions from this difference. The results of acute i.c.v. administration of $\alpha-\mathrm{MSH}$ are shown in Table 3. The results do not show any differences between $\alpha-\mathrm{MSH}-$ treated and saline-treated controls.

\section{Discussion}

Our new results show that continuous administration of the MC4 receptor antagonist HS014 causes substantial increase in food intake. It is interesting to note that the increase in food intake was not only observed after the first day of the infusion but progressively increased, reaching a maximum at Day 7. The maximum level of food intake was then maintained throughout the infusion period and additionally for 1 day after the termination of the infusion. On the 2nd day after the end of the infusion, the food-intake levels were drastically reduced and even fell significantly below the control levels on Day 21 . We had previously performed a 2 -week study with continuous infusion of HS014 in a limited number of animals (Kask et al. 1999). In comparison to this earlier study, our present data show a greater increase in the food intake but a similar increase in body weight. In the present study, we also followed the food intake for 12 days after the infusion was stopped. In contrast to our earlier study, in the present study the mini-pumps were actively stopped (in our previous study, the pumps were not disconnected and the end-point of that study was based on the pump manufacturer's given end-point). The results are also different: the rats in the previous study continued to overeat, whereas the rats in our present study stopped overeating 2 days after the infusion was stopped. The same dose of HSO14 and the same osmotic pumps were used in both studies. The overeating observed in the previous study after the predicted end-point of the infusion could be related to residual amounts of the substance leaking out of the pumps. Thus we conclude that chronic infusion of the MC4 receptor antagonist for 2 weeks in male rats does not lead to a permanent increase in food intake. It is noteworthy that no tachyphylaxis was observed after 2 weeks of administration of the MC4 receptor antagonist, which is in agreement with our previous studies (Kask et al. 1999, Skuladottir et al. 1999). The results also indicate that overeating and the subsequent increase in body weight caused by MC4 receptor blockage are reversible when the blockage is stopped.

The results on body weight show that there was already a clear and significant increase in body weight after 2 days of infusion of HS014. In line with the data on food intake, the rats continued to gain weight during the whole period and for 1 day beyond termination of the infusion. The amount of weight gain observed after the 12-day infusion is in line with our earlier infusion data for HS014, i.e. an approximately $20 \%$ increase in body weight after 2 weeks. After the infusion period, the rats lost weight rather rapidly for 4 days. On the following days, the weight loss was not as rapid as that in the first period, despite the fact that the food intake was lowered below control levels at Day 22. If the weight curves for the last 6 days of the study were to be extrapolated in a linear fashion, the HSO14 rats would need approximately one additional week (a total of 3 weeks after the infusion) to reach the same body weight levels as the controls.

There are some earlier pieces of evidence showing that ACTH may affect copulatory behavior in rats (Bertolini et al. 1975, Spruijt et al. 1985). This effect, however, was reported to be much less pronounced than the clear and undisputed effect of ACTH and $\alpha-\mathrm{MSH}$ on penile erection in male rats. Our new results indicate that acute administration of $\alpha-\mathrm{MSH}$ does not influence copulatory behavior in male rats. We are not aware of any tests having been conducted on the effects of $\alpha-\mathrm{MSH}$ on copulatory behavior prior this study. Most of the central behavioral effects of ACTH have been reproduced using $\alpha-\mathrm{MSH}$. No MC2 receptors (ACTH receptors) have been found in the brain and, as ACTH is processed into $\alpha-\mathrm{MSH}$, it has been assumed that the central effects of ACTH are mediated by the MC receptors. As neither $\alpha-\mathrm{MSH}$ nor HS014 was effective after acute administration in our study, we assume that the $\mathrm{MC}$ receptors, in particular the MC4 receptors, cannot be linked with copulatory behavior in male rats.

Obesity is also known to interfere with copulatory behavior in some animal models (Young et al. 1986, Hemmes \& Schoch 1988). Our results show no signs that copulatory behavior is affected by the long-term infusion of HS014 at any of the three investigation points, despite the obvious obesity that was observed in the rats when the infusion was stopped.

We have previously shown that it is unlikely that it is the MC4 receptor that is the mediator of the potent erectogenic effects of $\alpha-\mathrm{MSH}$. It is likely, therefore, that the MC4 receptor is not an important mediator of any of the effects of the melanocortins which have been observed in earlier studies in rats (Argiolas et al. 1988, Vergoni et al. 1998), rabbits (Bertolini et al. 1969) and humans (Wessells et al. 1998).

In summary, we have described the effects on food intake, body weight and copulatory behavior in male rats after continuous MC4 receptor blockage for 2 weeks and for 2 weeks after the treatment was stopped. The results indicate that $\mathrm{MC}$ receptors, and in particular the MC4 receptor, may not be a major mediator of effects on copulatory behavior in male rats. 


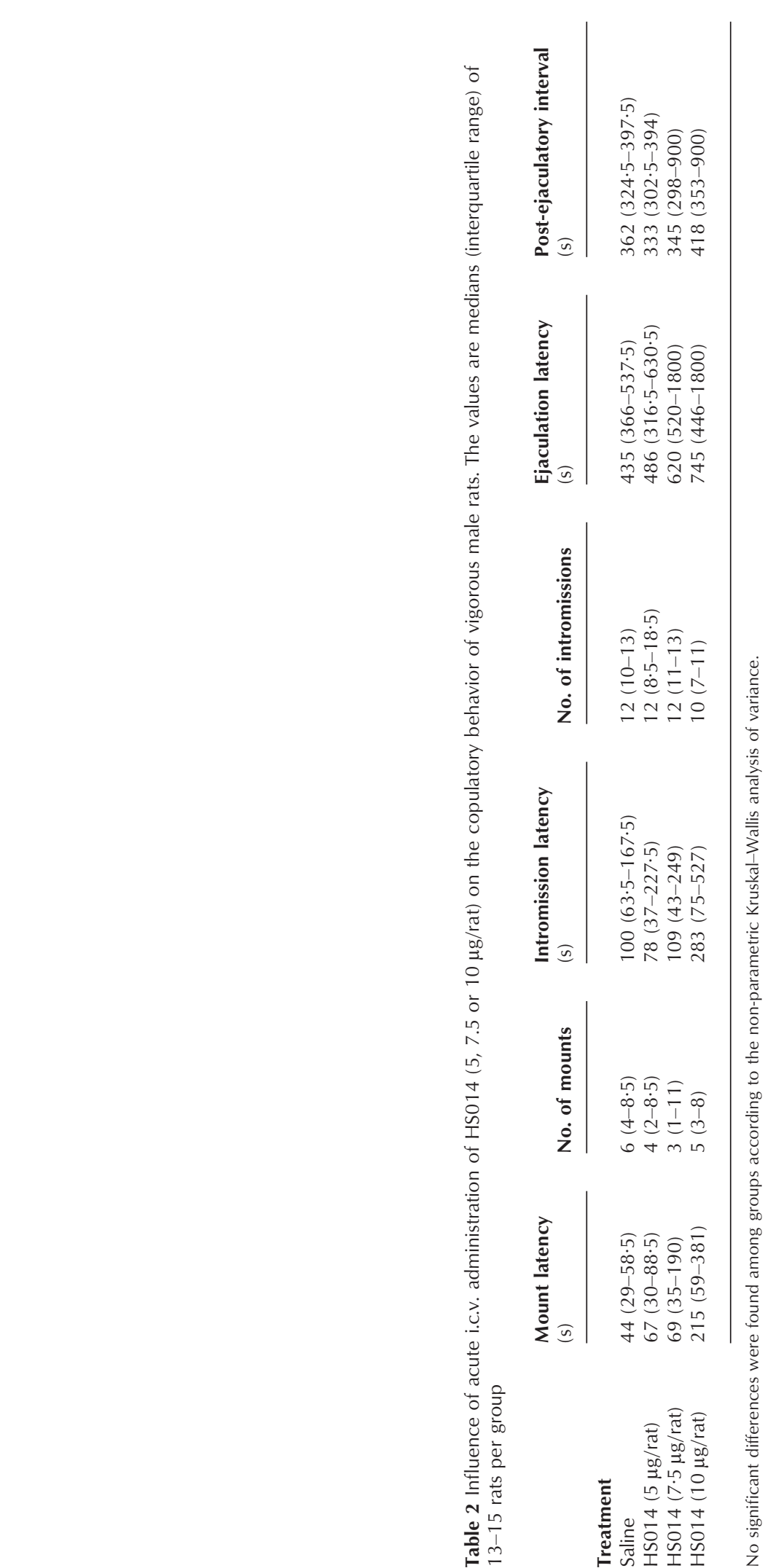




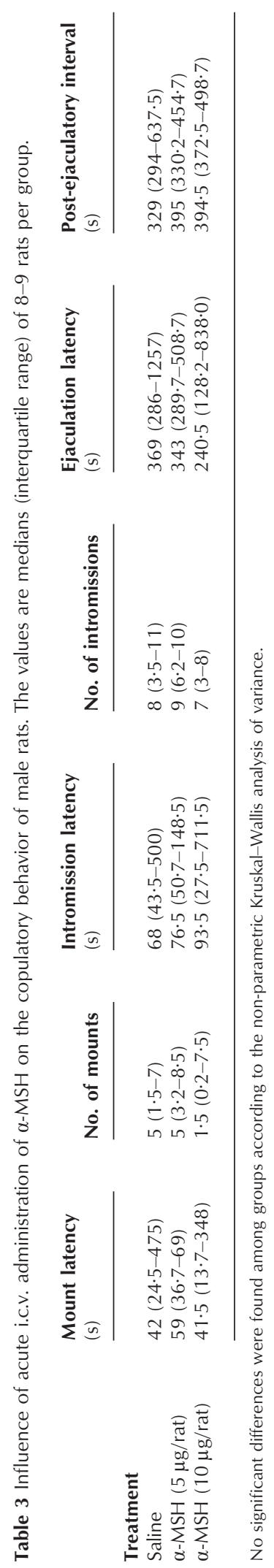




\section{Acknowledgements}

This study was supported by grants from the Swedish Medical Research Council (04X-05957) and from the Ministero dell'Università e della Ricerca Scientifica e Tecnologica (Rome). We thank Melacure Therapeutics AB (Uppsala, Sweden) for providing HS014. Dr Helgi B Schiöth was supported by the Swedish Brain Research Foundation.

\section{References}

Argiolas A, Melis MR \& Gessa GL 1988 Yawning and penile erection: central dopamine-oxytocin-adrenocorticotropin connection. Annals of the New York Academy of Sciences $\mathbf{5 2 5}$ 330-337.

Bertolini A, Gessa GL, Vergoni W \& Ferrari W 1968 Induction of sexual excitement with intraventricular ACTH; permissive role of testosterone in the male rabbit. Life Sciences 7 1203-1206.

Bertolini A, Vergoni W, Gessa GL \& Ferrari W 1969 Induction of sexual excitement by the action of adrenocorticotrophic hormone in brain. Nature 221 667-669.

Bertolini A, Gessa GL \& Ferrari W 1975 Penile erection and ejaculation: a central effect of ACTH-like peptides in mammals. In Sexual Behavior: Pharmacology and Biochemistry, pp 247-257. Eds M Sandler \& GL Gessa. New York: Raven Press.

Dewsbury DA 1972 Effect of tetrabenazine on the copulatory behavior in male rats. European Journal of Pharmacology 17 221-226.

Fan W, Boston BA, Kesterson RA, Hruby VJ \& Cone RD 1997 Role of melanocortinergic neurons in feeding and the agouti obesity syndrome. Nature 385 165-168.

Grill HJ, Ginsberg AB, Seeley RJ \& Kaplan JM 1998 Brainstem application of melanocortin receptor ligands produces longlasting effects on feeding and body weight. Neuroscience $\mathbf{1 8}$ 10128-10135.

Guarini S, Bazzani C, Cainazzo MM, Mioni C, Ferrazza G, Vergoni AV, Schiöth HB, Wikberg JES \& Bertolini A 1999 Evidence that the melanocortin 4 receptor mediates the hemorrhagic shock reversal caused by melanocortin peptides. Journal of Pharmacology and Experimental Therapeutics 291 1023-1027.

Hemmes RB \& Schoch R 1988 High dosage testosterone propionate induces copulatory behavior in the obese male Zucker rat. Physiology and Behaviour 43 321-324.

Huzsar D, Lynch CA, Faurchild-Huntress V, Dunmore JH, Fang Q, Berkemeyer LR, Gu W, Kesterson RA, Boston BA, Cone RD, Smith FJ, Campfield LA Burn P \& Lee F 1997 Targeted disruption of the melanocortin-4 receptor results in obesity in mice. Cell $\mathbf{8 8}$ 131-141.

Kask A, Rägo L, Mutulis F, Wikberg JES \& Schiöth HB 1998 Selective melanocortin 4 receptor antagonist (HS014) increases food intake in free-feeding rats. Biochemical and Biophysial Research Communications 245 90-93.
Kask A, Rägo L, Wikberg JES \& Schiöth HB 1999 Long-term administration of MC4 receptor antagonist HS014 causes hyperphagia and obesity in rats. Neuroreport 10 707-711.

Lipton JM \& Catania A 1997 Anti-inflammatory actions of the neuroimmunomodulator alpha-MSH. Immunology Today 18 140-145.

Lu D, Willard D, Patel IR, Kadwell S, Overton L, Kost T, Luther M, Chen W, Woychik RP, Wilkison WO \& Cone RD 1994 Agouti protein is an antagonist of the melanocyte-stimulating-hormone receptor. Nature 371 799-802.

Paxinos G \& Watson C 1982 The Rat Brain in Stereotaxic Coordinates. New York: Academic Press.

Poggioli R, Vergoni AV \& Bertolini A 1986 ACTH-(1-24) and alpha-MSH antagonize feeding behavior stimulated by kappa opiate agonists. Peptides 7 843-848.

Sachs BD \& Barfield RJ 1976 Functional analysis of masculine copulatory behaviour in the rat. Advances in the Study of Behavior 7 91-154.

Schiöth HB, Muceniece R, Larsson M \& Wikberg JES 1997 The melanocortin 1, 3, 4 or 5 receptors do not have a binding epitope for ACTH beyond the sequence of $\alpha-\mathrm{MSH}$. Journal of Endocrinology $15573-78$.

Schiöth HB, Mutulis F, Muceniece R, Prusis P \& Wikberg JES 1998 Discovery of novel melanocortin 4 receptor selective $\mathrm{MSH}$ analogues. British Journal of Pharmacology 124 75-82.

Skuladottir GV, Jonsson L, Skarphedinsson JO, Mutulis F, Muceniece R, Mutule I, Helgason J, Prusis P, Wikberg JES \& Schiöth HB 1999 Long term orexigenic effect of a novel melanocortin 4 receptor selective antagonist. British Journal of Pharmacology 126 $27-34$.

Spruijt BM, Hoglund U, Gispen WH \& Meyerson BJ 1985 Effects of ACTH 1-24 on male rat behavior in an exploratory, copulatory and socio-sexual approach test. Psychoneuroendocrinology 10 431-438.

Vergoni AV, Poggioli R \& Bertolini A 1986 Corticotropin inhibits food intake in rats. Neuropeptides 7 153-158.

Vergoni AV, Bertolini A, Mutulis F, Wikberg JES \& Schioth HB 1998 Differential influence of a selective melanocortin MC4 receptor antagonist (HS014) on melanocortin-induced behavioral effects in rats. European Journal of Pharmacology 362 95-101.

Vergoni AV, Bertolini A, Mutulis F, Wikberg JES \& Schiöth HB 1999 Selective melanocortin MC4 receptor blockage reduces immobilization stress-induced anorexia in rats. European Journal of Pharmacology 369 11-15.

Wessells H, Fuciarelli K, Hansen J, Hadley ME, Hruby VJ, Dorr R \& Levine NJ 1998 Synthetic melanotropic peptide initiates erections in men with psychogenic erectile dysfunction: double-blind, placebo controlled crossover study. Urology 160 389-393.

Young JK, Fleming MW \& Matsumoto DE 1986 Sex behavior and the sexually dimorphic hypothalamic nucleus in male Zucker rats. Physiology and Behavior 36 881-886.

Received 29 October 1999

Revised manuscript received 10 March 2000

Accepted 11 April 2000 